\title{
A construção do medo em It: $a$ coisa: reflexões sobre a narrativa cinematográfica de Andy Muschietti, à luz do gênero fantástico
}

\author{
Naiara Sales Araújo \\ Universidade Federal do Maranhão, Centro de Ciências Humanas, São Luís, MA, Brasil \\ ORCID: http://orcid.org/0000-0002-9362-559X
}

\section{José Antonio Moraes Costa}

Mestrando; Universidade Federal do Maranhão, Centro de Ciências Humanas, São Luís, MA, Brasil ORCID: http://orcid.org/0000-0003-4603-361X

\section{Resumo}

Em 2017, a obra literária It - a coisa (1986) de Stephen King transformou-se em produto audiovisual pelas mãos do cineasta Andy Muschietti. Nascido na Argentina, em 1973, Muschietti ganhou notoriedade no cinema por conta do filme de terror Mama (2013). Muschietti declara sua paixão pela obra de King desde os 14 anos e reconheceu o desafio de adaptar para as telas as mais de mil páginas do romance do escritor norteamericano. Nesse sentido, este artigo traz à baila reflexões sobre a construção do medo na narrativa cinematográfica It: $a$ coisa (2017). Para tanto, analisamos a película pelo viés do fantástico, a partir dos apontamentos de Lovecraft (1973), Todorov (1981), Bauman (2008), França (2017) e Araújo (2018). No campo do cinema, buscamos suporte em Aumont (1995) e Messias (2016). Defendemos que através do fantástico, é possível reconhecer a presença de recursos insólitos para construção do medo no filme. Assim, por ser um texto composto por sons, imagens e planos, a narrativa cinematográfica potencializa o pavor no espectador.

\section{Palavras-chave}

Medo. Cinema. Fantástico. Andy Muschietti.

\section{Introdução}

As narrativas fantásticas floresceram na Europa do século XIX. 0 pensamento romântico desse período histórico, que se contrapunha aos ideais racionalistas do Século 
das Luzes, foi essencial para que escritores como Théophile Gautier, Honoré de Balzac, Louis Lambert, Guy de Maupassant, E. T. A. Hoffmann e tantos outros buscassem, no fantástico, o escapismo para evocar temáticas fantasmagóricas, oníricas, mórbidas ou sobrenaturais.

Essas narrações fantásticas superaram o mundo superficial e ofereceram metáforas para ressignificação da realidade. As experiências advindas dessas histórias transcenderam o estritamente humano, elas aproximavam o indivíduo do sobrenatural. Os medos encobertos pela luz da racionalidade do século XVIII passaram a ser evocados por meio de histórias inexplicáveis, inverossímeis e inusitadas. Dessa maneira, o fantástico conseguiu rejeitar o rigor e a lucidez pregada pelos iluministas.

Ao longo dos séculos XIX e XX, muitas perspectivas já foram adotadas sobre a temática fantástica. As teorias estruturalistas de Tzvetan Todorov, a abordagem psicanalítica de Freud e o pensamento existencialista de Sartre, por exemplo, buscaram entender como esse gênero conseguiu construir narrativas com técnicas tão realistas ao mesmo tempo que abalava o realismo, introduzindo nessas narrativas realidades tão inadmissíveis.

Para Todorov (1981), uma narrativa é fantástica quando há presença de acontecimentos inexplicáveis pelas leis naturais. A história transita pela linha tênue entre a realidade e a imaginação, o palpável e o insólito. Essa impossibilidade de explicação dos fatos configura no texto fantástico a sensação de medo, visto que há uma quebra da lógica ou racionalidade de um acontecimento.

A partir disso, desvelaremos neste artigo alguns procedimentos usados para a construção do medo na narrativa cinematográfica It: a coisa (2017), dirigida por Andy Muschietti. Para atingir nossos objetivos, apresentaremos algumas considerações sobre o que é o medo e como as artes o representam. Em seguida, discorreremos sobre como as histórias fantásticas migraram do meio literário para o cinematográfico, e por fim, analisaremos algumas figurações do fantástico utilizadas para disseminar o pavor na película.

\section{Algumas considerações sobre o medo}

O medo é um sentimento comum aos seres humanos e a outros animais. $\mathrm{O}$ biólogo e estudioso do comportamento animal Walter Bradford Cannon "[...] observou que, em 
situações de ameaça, os mamíferos em geral apresentavam um conjunto de alterações fisiológicas provocadas pelo sistema nervoso simpático." (FRANÇA, 2017, p. 47). Os humanos, todavia, conhecem algo além disso: uma espécie de medo potencializado, que Freud (1996) chama de "medo derivado" (FREUD, 1996, p. 237). Para o psicanalista, esse sentimento é uma combinação entre a intensidade de nossa reação emocional diante de determinada situação - a morte, por exemplo - e nosso pouco conhecimento científico a respeito dessa situação. Esse entrelaçamento é o fator responsável pela intensidade das experiências com o sentimento do medo.

Além disso, o que mais nos amedronta é o fato de o medo estar ou existir concomitantemente em todos os lugares, pessoas ou coisas. Ele pode emergir de qualquer canto ou fresta de nossos lares e de nosso planeta: das ruas escuras ou das telas luminosas da televisão ou do cinema, dos nossos quartos ou cozinhas, das pessoas que encontramos e daquelas que não conseguimos perceber. Bauman (2008), grande pensador da pósmodernidade, defende que "Os medos são muitos e variados. Pessoas de diferentes categoriais sociais, etárias e de gênero são atormentadas por seus próprios medos" (BAUMAN, 2008, p. 31). Essas variações do medo são recorrentes no nosso objeto de estudo. Na narrativa audiovisual It: a coisa (2017), acompanhamos um grupo de crianças aterrorizadas diante de ameaças reais e supernaturais.

De acordo com o antologista Alberto Manguel (2005), por medo construímos sociedades com muralhas e fronteiras. Preocupamo-nos com regras científicas, leis, filosofias empíricas, nossa própria linguagem e, com exacerbada fé, acreditamos que haverá uma explicação para o incompreensível e para o indefinível. Contudo, basta uma noite escura, um ruído insuspeitado, um momento de descuido na escuridão, para que o pavor se instaure. Na narrativa cinematográfica em análise, o pavor se instaura ao longo da história, justamente, pela presença de elementos incompreensíveis e inexplicáveis.

As trevas, as bestas monstruosas, os seres fantasmagóricos, os cemitérios, os rituais mágicos, os bosques e ambientes escuros, tudo surge como elemento insólito e ativador do medo nas mais diversas culturas e comunidades. De modo semelhante, esses elementos serão evocados na construção do medo na narrativa fílmica de Andy Muschietti. Assim como o cineasta, o escritor H. P. Lovecraft (1973) recorreu àquilo que não podia ser explicado para aterrorizar seu público. Segundo este autor, desde os tempos antigos, a emoção mais forte da humanidade é o medo (LOVECRAFT, 1973). Nesse sentido, “[...] o medo está interligado aos mecanismos de proteção contra o perigo". (FRANÇA, 2017, p. 45). Ele 
relaciona-se com os nossos instintos de sobrevivência. As situações que envolvem o medo revelam a consciência de nossa finitude.

Convém destacar que o medo é uma emoção onipresente na história e nas produções da imaginação humana. Para Montaigne (1991), esse sentimento é capaz de modificar nossas crenças morais, comportamentos, cognições e percepções da realidade. A força do medo reside exatamente na possibilidade de ele aflorar, independentemente da racionalidade, razoabilidade e justeza das suas causas. Em nosso objeto de estudo, percebemos que Muschietti entrelaça as percepções de incerteza, perigo e desespero. Esses elementos são importantes na narrativa, pois, são eles que modificarão o comportamento dos personagens de It: a coisa (2017).

A fim de balizarmos essa assertiva, recorremos a França (2017), que distingue a incerteza e o perigo como catalisadores do medo. Dessa forma, esses dois elementos seriam a combinação perfeita para a emersão do medo. A sensação de perigo e de incerteza produz “[...] [o] que costumamos chamar de angústia - a experiência do medo onipresente, tão comum e constante em nossa sociedade contemporânea. 0 homem é bombardeado pela ideia contínua de perigo (...)" (FRANÇA, 2017 p. 48). Esse perigo é o alarme constante presente na narrativa de Muschietti. Os personagens vivem sempre em um estado de pânico e angústia diante dos acontecimentos do passado e do presente.

Nesse sentido, Bauman (2008) acrescenta que aquilo que não conhecemos e com que não conseguimos lidar nos causa pavor. Para o pensador, o medo seria um nome dado para nossa incapacidade de autodefesa. 0 medo do desconhecido é o elemento que mostra todas as fragilidades humanas e a brusca perda da racionalidade nas sociedades modernas. "O medo de uma catástrofe pessoal. 0 medo de se tornar um alvo selecionado, marcado para a ruína... 0 medo de cair de um veículo em rápida velocidade... 0 medo de ser deixado para trás. 0 medo da exclusão." (BAUMAN, 2008, p. 28). Este último é recorrente em It: a coisa (2017), pois o grupo de crianças que acompanhamos no filme vive à margem da sociedade da cidade ficcional de Derry.

Além disso, destacamos que, na narrativa de Muschietti, há um sentimento de impotência diante das situações descritas, às quais, portanto, os personagens têm de se adaptar. Dessa maneira, os eventos que deixam os personagens impotentes funcionam como mecanismos de expansão do medo no produto audiovisual. Nossa proposição é defendida por teóricos como Bauman (2008), que argumenta que nossa sociedade pósmoderna é um dispositivo que tenta tornar tolerável a vida com o medo. 0 incompreensível 
virou rotina, todavia sempre seremos assolados pela incapacidade de agir diante dos perigos que tememos. De acordo com a teoria baumaniana:

\begin{abstract}
Tendo assolado o mundo dos humanos, o medo se torna capaz de se impulsionar e se intensificar por si mesmo. [...] 0 medo nos estimula a assumir uma ação defensiva, e isso confere proximidade, tangibilidade e credibilidade às ameaças, genuínas ou supostas, de que ele presumivelmente emana. É nossa reação à ansiedade que reclassifica a premonição sombria como realidade cotidiana, dando ao espectro um corpo de carne e osso. 0 medo se enraíza em nossos motivos e propósitos, se estabelece em nossas ações e satura nossas rotinas diárias. [...] 0 ciclo do medo e as ações por ele ditadas não prosseguiriam ininterruptamente nem ganhariam velocidade se não extraíssem sua energia dos tremores existenciais. [...] Os tremores existenciais têm acompanhado os seres humanos por toda a sua história, e nenhum ambiente social em que as atividades existenciais humanas foram conduzidas ofereceu segurança garantida contra os 'golpes do destino' [...] (BAUMAN, 2008, p. 172, grifo do autor).
\end{abstract}

Para Bauman (2008), a noção de "destino" corresponde à impotência e à infelicidade das vítimas, mais que à própria crueldade do dano ou da perda. Nesse contexto, o destino se diferencia de outros desastres, pois nos ataca no oculto, sem aviso. Ele representa a ignorância e a incapacidade humana diante de determinadas situações/problemas. Os ciclos do medo na sociedade são incuráveis e, na verdade, estão arraigados atemporalmente. Chegaram para ficar - alguns podem estar adormecidos, esquecidos ou mesmo reprimidos por algum tempo, mas não esconjurados.

Resumindo as considerações apresentadas a partir das reflexões de Freud (1996), encontramos três fontes básicas para o medo. Para o psicanalista, o medo nos ameaça a partir do nosso corpo, a partir do mundo externo e a partir dos nossos relacionamentos (FREUD, 1996). Desta última fonte viria o medo mais penoso do que qualquer outro, embora ele não seja menos fatídico e inevitável que os descritos primeiro. As condições da sociedade individualizada são inóspitas à solidariedade. Não temos em que confiar, ficamos cada vez mais excluídos e afastados das relações humanas.

Ademais, de acordo com os estudos de Rogak (2017), "Os medos dominam cada segundo da nossa existência. Somos cercados por eles e vivemos em um arauto do terror." (ROGAK, 2017, p. 11). A lista de medos é longa: cobras, escuro, aranhas, coisas gosmentas, palhaços, pessoas, terapeutas, deformidades, lugares fechados, morte, etc. Temos medos diversos. As nossas vidas fluem ou se arrastam de um medo para outro durante nossa 
caminhada. Eles afligem nossas esperanças, e quando somos expostos, não sabemos enfrentar esse mal insuportável. Como exemplo dessa luta contra aquilo que adverso, destacamos Pennywise, a entidade maligna do filme. À luz dos teóricos elencados até aqui, consideramos esse personagem um catalisador dos medos de cada criança. A jornada dos personagens, em It: a coisa, é construída a partir das lutas físicas, emocionais, psicológicas e sobrenaturais contra esse monstro.

Sobre esse universo desconhecido do medo, é pertinente investigarmos na prática como ele é representado nas artes. A literatura, a pintura, a escultura ou o teatro usam desse elemento para a constituição de diversas obras. 0 Museu de Arte do Rio, por exemplo, em 2017, projetou uma exposição intitulada $O$ nome do medo, da artista mineira Rivane Neuenschwander. 0 trabalho reuniu casacos feitos com crianças a partir dos medos delas. Dessa forma, o projeto estimulou cerca de 200 crianças de 6 a 13 anos a listar, desenhar seus maiores temores e a confeccionar as peças. Esse exemplo faz alusão ao uso da arte para externalização dos conflitos interiores.

Já na arte literária, o medo remonta a tempos ancestrais. As lendas, mitos e rituais ocultos já utilizavam o medo e o horror como elemento das narrativas orais. As literaturas fantásticas e góticas potencializaram as obras do medo e evocaram o sobrenatural, a fim de impactar o leitor. Do mesmo modo, a arte cinematográfica buscou no gênero literário do terror o suporte perfeito para extrair os melhores efeitos dos medos humanos em suas narrativas audiovisuais. Segundo Jennifer Van Sijll (2017), estudiosa de cinema da Universidade do Sul da Califórnia (USC), “[...] o filme não é igual ao romance nem ao conto [...]" (SIJLL, 2017, p. 15). Ele possui elementos técnicos que o cineasta deve explorar. A capacidade de fazê-lo é o que diferencia o cinema da literatura. Sendo assim, a construção do medo na narrativa de Muschietti segue essa premissa. 0 cineasta explorou elementos fantásticos para a construção do medo. É isso que buscaremos desvelar no processo de análise do objeto deste artigo.

Diante do exposto, entendemos que a intensidade das sensações relacionadas à morte, ao perigo ou à dor consistiria na matriz ideal para as mais intensas experiências estéticas com o medo. Dessa forma, é relevante discutirmos as formas que a cinematografia encontrou para representar nas telas os medos explanados anteriormente. Adiante, discorremos sobre como o cinema fantástico e o cineasta Andy Muschietti incorporaram o cosmo do medo em suas produções audiovisuais. 


\section{As origens e o percurso da narrativa fantástica no cinema}

O fantástico esteve presente nas narrativas humanas desde a oralidade. Por meio dos mitos, rituais mágicos de civilizações antigas, evocações de entidades sobrenaturais e demônios, preservou-se a herança do sobrenatural. Com a poesia, as narrativas fantásticas ganharam uma materialização, ingressando na literatura como um dos maiores gêneros. Para Araújo (2018),

[...] o ser humano tende a possuir um certo fascínio por histórias que abordem o desconhecido, o mundo sobrenatural ou o insólito, de forma que as narrativas fantásticas, apesar dos esforços, nunca foram erradicadas efetivamente. (ARAÚJO, 2018, p. 92).

As produções fantásticas ganham notoriedade na maior parte dos escritos imaginários na Idade Média e Renascença. Durante os séculos XVII e XVIII, os escritos fantásticos se alinham ao gótico, multiplicando o interesse das pessoas pelo gênero devido às grandes produções literárias em torno do medo. Araújo (2018) observa que essa fusão do gótico com o fantástico objetiva causar os sentimentos de terror e horror. Ambientes como castelos antigos, florestas sombrias e cemitérios e temáticas satânicas são a base perfeita para as personagens melodramáticas e transtornadas.

Segundo o pesquisador Pereira (2013) “[...] o fantástico ganha força diante de uma sociedade racionalista. 0 imaginário traduzido na literatura do século XVIII chama atenção para elementos inquietantes e inexplicáveis pela lógica racional.” (PEREIRA, 2013, p. 3). Além da inquietação e dos fenômenos inexplicáveis, destacados por Pereira (2013), diversos estudiosos debruçaram-se sobre a narrativa fantástica e apresentaram outras características desse gênero, como: a hesitação do leitor e da personagem, problemáticas no foco narrativo, linguagem criativa e cheia de metáforas - capaz de gerar "efeitos fantásticos" como o duplo, a alienação e projeções sobrenaturais.

Na obra Introdução à literatura fantástica, de Todorov (1981), encontramos o que poderíamos chamar de o âmago do fantástico. Segundo os escritos dele, a hesitação do leitor diante de um fato que se apresenta como real e imaginário ao mesmo tempo é a origem do fantástico (TODOROV, 1981). Ele estabelece algumas noções para compreendermos o gênero: 
Num mundo que é exatamente o nosso, aquele que conhecemos [...], produz-se um acontecimento que não pode ser explicado pelas leis deste mesmo mundo familiar. Aquele que o percebe deve optar por uma das duas soluções possíveis; ou se trata de uma ilusão dos sentidos, de um produto da imaginação e nesse caso as leis do mundo continuam a ser o que são; ou então o acontecimento realmente ocorreu, é parte integrante da realidade, mas nesse caso esta realidade é regida por leis desconhecidas para nós. [...] 0 fantástico é a hesitação experimentada por um ser que só conhece as leis naturais, face a um acontecimento aparentemente sobrenatural. (TODOROV, 1981, p. 30-31).

As reflexões de Todorov (1981) mostram que o fantástico se alimenta dos conflitos entre o real e o possível. Assim, esse gênero se adequou muito bem às artes literária, teatral e cinematográfica. A partir dessas características, o cinema fantástico surge como a arte que consegue domesticar os corpos, segundo Messias (2016). Concordamos com essa afirmação, devido à capacidade que as imagens têm de impactar o espectador com aquilo que está sendo narrado imageticamente. Esse argumento é corroborado pelo crítico de cinema Jacques Aumont (1995). Ele nos pondera:

É importante observar que reagimos diante da imagem fílmica como diante da representação muito realista de um espaço imaginário que aparentemente estamos vendo. Mais precisamente, como a imagem é limitada em sua extensão pelo quadro, parece que estamos captando apenas uma porção desse espaço. (AUMONT, 1995, p. 21).

De acordo com Aumont (1995), alimentando-se desses conflitos, a arte cinematográfica fez muito sucesso após a Segunda Guerra Mundial. Nesse período, a humanidade estava aterrorizada e inconformada com os extremos das atrocidades humanas. Diante disso, a cinematografia ganhou grande notoriedade graças a seu poder catártico, combinando o sobrenatural, o burlesco, o inexplicável e o monstruoso. Essas combinações são recorrentes na produção de Muschietti. Em seu produto cinematográfico, o cineasta aproveita-se da temática do sobrenatural para explorar os medos e angústias do ser humano. Dessa forma, terminamos por enquadrar It: a coisa dentro do campo do fantástico, permitindo-nos esta análise.

Encontramos uma das muitas definições para fantástico no cinema em Aumont e Marie (2001), para os quais “[...] o cinema fantástico é produzido em uma obra de ficção quando um acontecimento inexplicável é relatado ou representado." (AUMONT; MARIE, 2001, p. 118). A partir disso, o fantástico serviu de grande arcabouço para diversas obras 
produzidas desde as origens do pré-cinema $^{2}$. O plano cinematográfico é capaz de representar as figuras insólitas que estão enraizadas nesse gênero. A narrativa de Muschietti é entrelaçada de efeitos do fantástico a fim de construir o medo. Deparamo-nos, ao longo do filme It: a coisa, com o insólito - monstros humanos e sobrenaturais, espaços assombrados e sofrimentos físicos e psicológicos, que desencadearão os diversos medos nos personagens.

O especialista em cinema Jacques Aumont (1995, p. 182) aponta que, a fim de alcançar os efeitos de terror, no cinema se utiliza uma série de aparatos técnicos como "[...] a superfície de enquadramentos, efeitos de realce, fundos luminosos, gráficos e geométricos, linhas oblíquas e aproximações de planos." (AUMONT, 1995, p. 182). Com todos esses métodos, busca-se apontar para os medos enraizados - os pontos de pressão - com os quais temos que aprender a lidar. Da mesma forma que o efeito fantástico provoca uma desestabilização na narrativa literária, a produção cinematográfica de Muschietti extrai seus melhores efeitos dos medos sobrenaturais e humanos, usando uma linguagem própria, porém com elementos alusivos e recorrentes da teoria fantástica.

O fantástico destacou-se no início do século XIX. Por meio dele, buscou-se o inverossímil, o imaginativo, o estranho, o monstruoso para debater sobre coisas que não condiziam com a realidade. Explicações de que a ciência não poderia dar conta - como ainda não dá - mistérios, incongruências e absurdos. Segundo Messias (2016), “[...] o fantástico vai surgir a partir de 1850, concomitantemente aos avanços científicos e ao discurso positivista desbravando o terreno que a ciência não ousava explicar." (MESSIAS, 2016, p. 275). Para o homem do século XIX, o aparelhamento do que denominamos de pré-cinema oportunizava um encanto e uma magia. Ao mesmo tempo, era um objeto de extravasamento dos medos.

As criações fantásticas ganharam corpo na cinematografia, de forma mais enfática, no início do século XX. O jovem Méliès ${ }^{3}$ ficou fascinado pelo recurso imagético e iniciou a apresentação dos primeiros filmes. Messias (2016) relata em suas pesquisas que a produção cinematográfica Viagem à lua, de 1902, inspirada nos escritos de Júlio Verne, é um exemplo importante do fantástico e da ficção científica audiovisual. De acordo com Sabadin $(2000)^{4}$,

\footnotetext{
2 "Era todo o aparato e maquinarias das mais diversas do século XIX, frutos de um pensamento engenhoso e criativo que buscava trabalhar - ainda que muitas vezes em nome da ciência - com a imagem em movimento, a luz, a sombra e a cor. " (MESSIAS, 2016, p. 276).

3 Georges Méliès, 1861-1938, foi um precursor da fabulação e da ficção na mídia cinematográfica, que, em pouco tempo, conquistaria todos os recantos do globo.

4 SABADIN, Celso. Vocês ainda não ouviram nada. A barulhenta história do cinema mudo. São Paulo: Lemos Editorial, 2000. Apud Messias (2016).
} 
citado por Messias (2016), "Parecia inacreditável. O cinema ainda não havia completado sete anos de idade e já exibia seres lunares, viagens desconhecidas, ambientes enigmáticos e povos nunca vistos." (SABADIN, 2000, p. 67-68 apud MESSIAS, 2016, p. 286).

De acordo com Messias (2016), muitos críticos afirmam que o cinema se origina atrelado ao realismo, contudo as primeiras imagens moventes pelo cinematógrafo traziam como figurações caixas mágicas e trens fantasmas. A plenitude do fantástico no cinema ocorreu por volta dos anos de 1930. Uma série de monstros da Universal Studios invadiu a cinematografia e evidenciou a ambivalência dos seres fantásticos nas películas. Na visão de Messias (2016), esses monstros eram "humanos por um lado e diabólicos por outro" (MESSIAS, 2016, p. 289). Muschietti propõe uma obra fílmica que gera essa duplicidade destacada por Messias (2016). As inquietações e hesitações são basilares nesse produto audiovisual. Sendo assim, o cineasta operacionaliza características fundamentais do gênero fantástico.

Complementando essa visão, Santana (2007) comenta: “O gênero cinematográfico de horror descende diretamente da literatura de terror do século XIX, esta nascida no seio da literatura fantástica." (SANTANA, 2007, p. 219). Na visão desse crítico de cinema, a ligação do cinema de horror com o fantástico possibilitou que o cinema idealizasse ambientações sobrenaturais. Elas serviram de inspiração para epopeias fantásticas da década de 1930 como A carruagem fantasma, A queda da casa de Usher e Vampyr. Na década de 1940, há o apogeu dos monstros clássicos como Frankenstein, Drácula e Lobisomem. Na década de 1950, a geração pós-guerra apresenta os seres alienígenas nas suas narrativas.

As décadas finais do século $\mathrm{XX}$ continuam produzindo narrativas evocando os monstros sobrenaturais, porém esses seres cederam lugar à presença do monstro humano. Para Messias (2016), “As produções apresentavam personagens com comportamentos psicóticos, perversos e fóbicos. As narrativas eram produzidas em torno do corpo, de seus resíduos, dejetos e limitações, bem como as angústias humanas." (MESSIAS, 2016, p. 314). Nesse período, produções como Carrie, a estranha infestam o cinema e se popularizam dentro do gênero horror. Corroborando o argumento expresso, Ramos (2002) afirma:

0 espectador somente sente medo se sabe que deve senti-lo. [...] se costuma criar a existência de um perigo (um monstro, um assassino), recriar o ambiente (a noite, a escuridão), somar a ameaça sonora (sons de origem desconhecida, música que manipula a emoção) mais a iluminação (muitas vezes de baixo, recortada) e a partir daí se pode disparar o susto. (RAMOS, 2002, p. 564). 
Diante do exposto, percebemos que com os confusos estados de espírito do sujeito da pós-modernidade, o fantástico no cinema do século XXI buscou outras vertentes. De acordo com Bauman (2008), vivemos em tempos angustiantes, com deslizantes formas no comportamento humano e suas relações sociais. Essas problemáticas são corporizadas no fantástico por meio do medo, fobias, paranoias, catástrofes e ataques terroristas. Isso originou na sociedade pós-moderna a constante sensação de perigo iminente.

Para o crítico cinematográfico Messias (2016), o cinema fantástico expandiu-se, freneticamente, após o atentando de 11 de setembro de 2001. De acordo com esse pesquisador,

[...] uma parte representativa do cinema fantástico no século XXI passou igualmente a ser questionador[a] do poder político e militar dos Estados Unidos e, de forma geral, dos blocos hegemônicos do planeta. Uma das consequências do atentado às torres gêmeas foi uma maior exposição das feridas narcísicas da humanidade, já abertas de alguma forma, e, nesse sentido, pode-se dizer que o cinema fantástico anterior conseguiu esboçar possíveis fatalidades por meio de um 'caráter premonitório'. (MESSIAS, 2016, p. 333).

Percebemos que o apavorante nas origens do cinema tem menos relevância hoje para os espectadores, nas palavras de Messias (2016), “[...] não com referência aos recursos de montagens e de efeitos especiais, que mudaram enormemente, mas, sim, aos enredos dos filmes, que naquela época costumavam se filiar ao gótico." (MESSIAS, 2016, p. 340). Com as transformações constantes nas sociedades e o advento das revoluções tecnológicas, as narrativas do cinema fantástico focalizaram as questões da exteriorização dos conflitos humanos. A obra de Muschietti se enquadra nessa proposta, visto que aí encontramos traumas que são projetados no próprio corpo, e não apenas reflexos de monstruosidades e entidades sobrenaturais. Retornamos a Messias (2016) para reforçar nossa tese; ele nos explica:

Ainda que no cinema atual haja novos 'Frankensteins' nos impelindo a questionar o mundo dos sentimentos, ganharam força criaturas que nos despertam para o frenesi das sensações e ultrapassam os limites corporais, em que o sujeito está a um passo de ser o hospedeiro do monstro, quando não é, ele mesmo, o monstruoso. (MESSIAS, 2008, p. 342, grifo nosso). 
Assim, verificamos que o cinema fantástico foi movido por um desejo de impressionar os sentidos e as sensações, de extravasar o medo e o horror diante das problemáticas humanas. De modo semelhante, a produção cinematográfica de Muschietti nos desvela essa urgência em retratar um mundo já conhecido na literatura, mas paradoxalmente, tão incompreensível, inesperado e grotesco, fazendo com que olhemos maravilhados, mas ao mesmo tempo amedrontados para It: a coisa. 0 escritor e ensaísta Stephen King (2003), num estudo crítico sobre o gênero horror na literatura e no cinema, destaca que "[...] um crítico de cinema chegou a chamar o ato de assistir a um filme de 'sonhar com os olhos abertos'." (KING, 2003, p. 101).

Dessa maneira, o gênero fantástico criou um universo capaz de ressignificar as frágeis subjetividades do homem. Para Messias (2016) "Somos como os garotos das Crônicas de Nárnia, que atravessamos o guarda-roupa para fugir da segunda guerra, mas adentramos em um mundo tão perigoso quanto." (MESSIAS, 2016, p. 335). Sendo assim, acreditamos que as narrativas fantásticas surgem como meio de evasão dos problemas reais, mas que o imaginário configurou um mundo tão sombrio e sinistro quanto o mundo do qual buscamos fugir. Doravante, refletiremos sobre como esse fantástico auxilia na construção do medo no filme de Muschietti.

\section{Figurações do fantástico na construção do medo em It: a coisa (2017)}

Baseamo-nos nas reflexões de Messias (2016), que nos afirma que, para iniciar qualquer processo de análise fílmica, devemos observar primeiramente o enredo. It: a coisa (2017) narra a história de um grupo de sete adolescentes de Derry, uma cidade fictícia no Maine, Estados Unidos (EUA), que formam o autointitulado clube dos otários. Um momento em que o insólito aparece, instaurando o fantástico, é, por exemplo, quando descobrimos que a cidade é assombrada por uma entidade sobrenatural que ataca, especialmente, crianças, a cada 27 anos. Mesmo consciente disso, curiosamente, a população permanece na cidade, colocando em risco a vida de toda a comunidade infantil.

Na narrativa cinematográfica, a pacata rotina urbana é abalada quando crianças começam a desaparecer. Encontram-se apenas partes de seus corpos largadas na cidade. Após tomar conhecimento disso, os integrantes do clube dos otários acabam ficando face a face com o responsável pelos crimes: o palhaço Pennywise. Esse monstro maligno é conhecido a partir do sumiço de Georgie, irmão caçula do protagonista do filme que sofre 
com a gagueira. Ao longo da obra, percebemos que as crianças não somente sofrem ataques do palhaço, mas também necessitam lidar com a violência de jovens cruéis da escola, além dos problemas familiares.

O filme traz à baila, com forte dramaticidade, temáticas como bullying, assédio sexual, racismo e violência doméstica. Verificamos que há recursos do fantástico, visto haver elementos que provocam a incoerência de eventos do cotidiano. 0 poder do monstro sobrenatural do esgoto é obtido a partir do medo e miséria que são reproduzidos pela pequena cidade de Derry. Tudo é causado por pessoas reais que apresentam alguns comportamentos: o pai que acredita ter direito sobre o corpo da filha. 0 adolescente que reproduz a violência física sofrida em casa nas crianças menores na escola. A criança negra que é perseguida pela sua cor. 0 jovem que se torna hipocondríaco por influência materna.

A produção cinematográfica foca na história dos personagens durante a infância objetivando o aprofundamento da exposição do medo dos personagens, visto que o texto literário do qual provém a adaptação fílmica é extenso e supercomplexo. 0 filme acaba com a descoberta de que Pennywise não poderá se alimentar das crianças, pois elas superaram os medos. Numa luta corporal, elas jogam o monstro em um poço.

Partindo desse rápido olhar sobre o enredo de Muschietti (IT..., 2017), observaremos a construção do medo analisando três aspectos importantes do filme: a estranha cidade de Derry, uma casa assombrada que os personagens visitam e o monstro sobrenatural. Esses temas na película levam à inserção do filme no gênero fantástico.

Em primeiro lugar, levantaremos alguns apontamentos sobre a cidade de Derry, o lugar onde se passa toda a história. Ela é o palco de diversos eventos inverossímeis. É nesse espaço que os protagonistas do filme se deparam pela primeira vez com os eventos sobrenaturais, fatos que mudam o cotidiano racional e os fazem entrar em uma aventura para destruir uma entidade do mal. A construção do espaço urbano é feita sob o ponto de vista sombrio e imaginativo do cineasta.

A importância da caracterização da cidade a fim de atingir o medo na obra cinematográfica é um dado irrefutável: locais lúgubres anunciam as tragédias que ocorrerão; sons perturbadores, atmosferas sinistras amplificam a letalidade do monstro Pennywise. As áreas do espaço urbano fora da autoridade da lei estimulam o medo e fantasias irracionais. O professor e pesquisador Júlio França (2017) faz as seguintes observações sobre o uso dos espaços terríveis - locus horribilis -, como potencializadores do medo no gênero fantástico: 
O locus horriblis é um elemento tão fundamental quanto a caracterização das personagens monstruosas. A capacidade do monstro de aterrorizar é quase sempre potencializada pelo espaço narrativo[,] que, longe de ser apenas um elemento constitutivo, pode se transformar em um topo figurativo, configurando-se, em si mesmo, como fonte de significação. (FRANÇA, 2017, p. 85, grifo do autor).

Esse argumento evidencia que o espaço de Derry se torna o centro da trama, porque desde a origem da cidade o mal existe lá. Isso torna a própria cidade uma personificação do mal. A cidade, em alguns momentos, assume significado grande ou até maior do que o de alguns personagens. Esse fato se comprova por meio dos interlúdios entre as cenas, que exploram a cidade desde a sua fundação. Observamos a preocupação do cineasta em destacar a importância da cidade, ao apresentar uma descrição de suas origens por parte de um dos protagonistas - Ben Hanscom:

- Esse é o estatuto do município de Derry. É muito interessante! Derry era um campo de armadilha para castores. Noventa e uma pessoas estavam na fundação da cidade, mas no inverno daquele ano, desapareceram sem deixar rastros. Todos sumiram! Houve rumores de que foram os índios, mas não havia sinal de ataque. Todos acham que foi uma praga, doença da cidade; mas o que parece é que todos acordaram e foram embora da cidade. A única pista foi um rastro de roupas com sangue que ia até um poço. Derry é um poço de mistérios não resolvidos. (IT..., 2017, : doc. não paginado).

Outro aspecto se refere à população que habita Derry. Constatamos que, no filme, as pessoas apresentam uma insensibilidade; são más e pouco admiráveis. Os próprios pais dos protagonistas são representados de forma assombrosa. Eles não demonstram interesses nos problemas dos filhos. Outros, demonstrando interesse excessivo pelos problemas dos filhos, os prejudicam e os humilham. 0 clima de insegurança na cidade é mais um sinal de como Derry emerge como elemento insólito na potencialização do medo. 0 cineasta apresenta a cidade como personificação das monstruosidades sobrenaturais e humanas.

Segundo um artigo publicado em 2017, no site oficial do escritor Stephen King idealizador da obra original -, apesar de aparentemente ser uma cidade comum, Derry tem, atrás de seus quintais com a grama bem aparada e a aparente tranquilidade dos moradores, um passado trágico e uma história que reflete toda a maldade que parece se esconder em suas vielas obscuras. 
Os visitantes da cidade têm a sensação de que algo não está certo. Destaca-se que a quantidade de homicídios é muito mais assombrosa que em qualquer outra cidade da região, bem como a taxa de desaparecimento de crianças, que é constante. Ninguém consegue explicar os estranhos eventos, e os moradores limitam-se a falar sobre os desaparecimentos.

Outros lugares da cidade são relevantes para intensificação da tensão e do medo: a biblioteca; a velha indústria abandonada; a casa abandonada, na qual uma das lutas é travada com o monstro da história; o canal de esgoto, com o lago que o cerca, e o quarto de Beverly. Gaston Bachelard (2008), estudioso do espaço na narrativa, advoga que os espaços físicos, por exemplo, as casas são "[...] os locais de nossa vida íntima [...]" (BACHELARD, 2008, p. 20), uma vez que os espaços guardam boas ou más experiências e memórias; na proporção em que são evocados nas narrativas, os espaços sinistros potencializam o medo ao retomar essas más lembranças, como acontece na película.

França (2017) também participa desse debate sobre espaço e medo, afirmando que nas narrativas fantásticas "Os ambientes podem variar conforme o contexto cultural de cada narração, mas tanto regiões selváticas quanto áreas rurais e os grandes centros urbanos são descritos como locais aterrorizantes" (FRANÇA, 2017, p. 24), já que as intensidades imagéticas de suas construções representam um locus horribilis. 0 espaço é uma metáfora que descreve como vemos a nós mesmos e ao mundo, pois ele nos apresenta algo muito mais sombrio do que aquilo a que estamos acostumados.

Além disso, o espaço é onde o insólito acontece. Todorov (1981) usa o termo insólito para se referir à presença do sobrenatural em obras fantásticas. Ele é capaz de despertar tanto no leitor quanto no espectador o sentimento do inverossímil, do impossível ou do inusitado. Os acontecimentos insólitos em Derry, como crianças desaparecidas inexplicavelmente, violência em excesso, visões de entidades sobrenaturais, ruas e locais escuros com monstros humanos, exemplificam o espaço como suporte para o insólito.

À luz dos argumentos, defendemos a tese de que Derry representa um ativador do medo na obra fílmica, visto que os acontecimentos insólitos demonstram as dificuldades em distinguir imaginação e realidade. 0 mal presente na cidade se personifica no próprio monstro que aterroriza o clube dos otários. Isso explica o porquê de a entidade habitar esse ambiente sinistro. Além da cidade, há mais fatos insólitos, que provam a construção do medo por meio do fantástico. 
Analisamos também a casa assombrada da rua Neibolt, enquanto figuração fantástica. As casas mal-assombradas são espaços onde costumam acontecer eventos insólitos sem que se encontre uma causa física para esses eventos. 0 tema das casas malassombradas é capaz de exercer tanto fascínio sobre os espectadores que, com o passar do tempo, constituiu um subgênero do cinema fantástico - o cinema gótico. No produto audiovisual, há a presença de uma casa abandonada onde ocorre uma série de eventos inexplicáveis. Estes instauram o fantástico no filme.

Os personagens decidem visitar o lugar a fim de solucionar os eventos causados pelo palhaço Pennywise. A casa configura-se como o habitat da entidade maligna. As sequências de ampliação do medo se passam nesse espaço. Os estranhos eventos que ocorrem no interior da residência parecem ora ações geradas no inconsciente das crianças, ora realidade produzida pelo aparecimento da entidade sobrenatural. 0 crítico e historiador de cinema da França Marcel Martin (2003) nos adverte que "O cinema é uma linguagem. 0 filme é uma escrita em imagens." (MARTIN, 2003, p. 22). Diante disso, a imagem fílmica representa a realidade material, estética e intelectual, pois ela é capaz de afetar nossos sentimentos e assumir uma significação ideológica e moral.

A partir desse evento, mais uma vez o fantástico se instaura na narrativa. Os personagens não conseguem discernir entre a realidade e a imaginação. Em um dos ataques, o monstro saindo de uma geladeira velha questiona Bill: “- Eu não sou real o suficiente para você, Billy? Ainda não sou?! Eu fui real suficiente para o Georgie!” (IT..., 2017, doc. não paginado. ). Esse elemento demonstra o efeito fantástico. Por meio do espaço e de elementos insólitos, o cineasta consegue ampliar o estado de tensão e a progressão do medo na casa assombrada. De acordo com os estudos de Todorov (1981):

\footnotetext{
Existe uma outra variedade do fantástico em que a hesitação se situa entre o real e o imaginário [grifo do autor]. No primeiro caso, duvidava-se não de que os acontecimentos tivessem sucedido, mas de que nossa compreensão tivesse sido exata. No segundo, pergunta-se se o que acreditamos perceber não é de fato fruto da imaginação. (TODOROV, 1981, p. 42).
}

A casa aparece pela primeira vez quando o personagem Eddie vê um homem leproso. Ela guarda um poço, e de acordo com as pesquisas de Ben, esse seria o local que o monstro habitaria e pelo qual se locomoveria em Derry. 0 ambiente é bem sinistro: muita sujeira, escuridão, madeira apodrecida, ruídos estranhos, mobília velha, teias de aranhas, 
colchões mofados, cadáveres, caixões e objetos sinistros. É nesse cenário que se encapsula a maleficência da presença de Pennywise. Para o professor Júlio França (2017),

Toda caracterização torna o espaço bastante ameaçador, mesmo sem a presença de um elemento fantasmagórico. Quando eles aparecem, apenas corroboram o efeito intenso já provocado pelos elementos naturais. [...] 0 elemento fantasmagórico que se alia à descrição espacial, potencializando, dessa forma, o terror provocado. (FRANÇA, 2017, p. 99).

A descrição de França (2017) nos ajuda a perceber que o filme é uma expressão artística que se caracteriza também por descrever, com minúcia, espaços e personagens. Esses elementos, aliados com a linguagem cinematográfica - imagens, movimentos, planos, tomadas e cortes -, são organizados para produzir a sensação de medo e podem ser uma representação do real ou do imaginário.

O último elemento de produção do medo e do fantástico que destacaremos é a figura do palhaço. 0 monstro presente na história assume a forma de um palhaço; contudo, para se alimentar de suas vítimas, transforma-se no medo de cada uma delas. Para França (2017), "Os monstros são a corporificação metafórica dos desejos, das ansiedades, das fantasias, e, sobretudo, dos medos [...]" (FRANÇA, 2017, p. 37). De modo semelhante, essa corporificação de medo, descrita por França (2017), reaparece na história de Bill.

Para Christian Metz (1980), “[...] o filme é uma obra de arte e o é sempre, por sua qualidade e seu sucesso, ou simplesmente por sua natureza: há sempre uma intenção estética e criativa do autor." (METZ, 1980, p. 14). Concordamos com Metz (1980), pois Muschietti nos apresenta um personagem traumatizado pelo assassinato de Georgie, seu irmão mais novo, pela entidade maligna. Na história, Pennywise assume a forma de um palhaço para Georgie. Porém, suas características são sombrias. Seu habitat são os esgotos. Ele procura ambientes lúgubres, imundos e deteriorados para atrair suas vítimas. É para os locais do esgoto de Derry que, na primeira cena do filme, o corpo de Georgie é arrastado pela criatura.

A morte prematura de Georgie, a forma inexplicável do desparecimento do corpo do garoto e a culpa atormentam o protagonista. Esse trauma é a forma que Pennywise encontra para se corporificar, a fim de causar pavor em Bill. Percebemos que o monstro inflige um tormento constante no personagem, por meio de aparições para Bill como Georgie, porém com um corpo todo deformado. 
Eddie, outro membro do clube dos otários, também sofre ataques constantes do palhaço maligno. Todavia, vemos que Pennywise usa de novas artimanhas. 0 garoto apresenta uma psicopatologia chamada de hipocondria. É uma obsessão com a ideia de ter um problema médico grave. Ele tem compulsivos pensamentos sobre o próprio estado de saúde. Por isso, frequentemente, está na farmácia comprando remédios.

A hipocondria de Eddie é a base para que o palhaço o assombre. A fim de atingir seu objetivo, a criatura se corporifica na figura de um homem leproso, que tenta atacá-lo em várias cenas. Para Messias (2016) o cinema fantástico, para construir narrativas do medo, usará da "[...] confusão da imaginação com a realidade: zona de encontro e reencontro entre o imaginário e o real." (MESSIAS, 2016, p. 33). Essa ambivalência é justamente o embate pelo qual Eddie passa. 0 homem acometido de lepra é real ou a psicopatologia do garoto propicia os devaneios? Esses eventos que apontamos como sobrenaturais e insólitos são marcas do fantástico na narrativa fílmica.

Quanto a Beverly, única menina do grupo, os abusos físicos e sexuais são a forma que o monstro encontra para lhe causar pavor. Os traumas transformaram a jovem em um alvo fácil para que a entidade maligna se corporificasse. Assim, o monstro sobrenatural desaparece, e emerge o humano, na figura do pai da menina. 0 ensaísta Francis Vanoye (2012), em seu estudo sobre a análise fílmica, assinala que as “[...] narrativas de personagens têm um caráter subjetivo. Elas tendem a narrar aquilo que o personagem está sofrendo." (VANOYE, 2012, p. 44). Vanoye (2012) defende que no ato narrativo do cinema, essa voz dos personagens, também, possui uma função de direção indireta ao espectador.

O especialista em cinema Jacques Aumont (2013) aponta que, a fim de alcançar os efeitos de terror, o cinema se utiliza "[...] da superfície de enquadramentos, efeitos de realce, fundos luminosos, gráficos e geométricos, linhas oblíquas e aproximações de planos." (AUMONT, 2013, p. 182). Com todos esses métodos, aponta-se para os medos enraizados os pontos de pressão - com os quais temos que aprender a lidar. Da mesma forma que o efeito fantástico provoca uma desestabilização na narrativa literária, os filmes de terror extraem seus melhores efeitos dos medos sobrenaturais e humanos, usando a própria linguagem cinematográfica.

O que é significativo para nossa análise é que a ação do sobrenatural tem origem na própria ação humana. A monstruosidade e o medo se ampliam na narrativa, à medida que o pai abusa do corpo e atormenta a mente da adolescente. Logo, concluímos que o pai é o próprio Pennywise, conforme observamos neste diálogo do filme: 
- Onde você vai, saindo assim de fininho?

- Para lugar nenhum, pai.

- Você está toda arrumada?!

- Não estou arrumada, pai! Me visto assim todos os dias.

- Vem cá! Você sabe que eu me preocupo com você, Beverly?! [Segurando com violência a mão da menina] As pessoas da cidade me contaram umas coisas sobre você! Andando com um monte de meninos!

- Eles só são meus amigos, eu juro!

- Por que você tem poemas escondidos na sua gaveta de calcinhas?! Você anda fazendo coisas de mulher com esses meninos no bosque?! [Aperta com raiva a mão da menina] Você ainda é minha menininha, Beverly?! Aqueles meninos sabem que você é minha?! [Parte com violência para agredir a adolescente] (IT..., 2017, doc. não paginado).

Os argumentos expostos nessa citação se correlacionam com o pensamento de Messias (2016): “[...] a presença de um monstro humano pode ser entendida como uma forma de se colocar o espectador no lugar da vítima e para que se sinta imerso nas sensações de um medo inexplicável." (MESSIAS, 2016, p. 328). As angústias, fragilidades e limitações impostas a Beverly nos mostram a preocupação do cinema moderno em explorar o medo, a partir de temáticas polêmicas e por meio de narrativas fantásticas.

Desse modo, verificamos que o filme consegue construir um estado de tensão, pavor e medo ao longo de toda a trama, ao usar temáticas como uma cidade maligna, uma casa assombrada e monstruosidades sobrenaturais e humanas.

\section{Considerações finais}

A partir da análise aqui desenvolvida, observamos que no filme It: a coisa (2017), o medo e a hesitação são elementos fundamentais para a existência de uma narrativa fílmica dentro dos limites do fantástico. Além disso, constatamos que a película pode ser enquadrada na categoria fantástica, uma vez que a narrativa é construída através da tensão entre o real e irreal. As temáticas da cidade maligna, da casa assombrada e de um palhaço sobrenatural comprovaram-se como formas principais de instaurar o insólito no filme. Percebemos o gênero fantástico emergindo na narrativa como uma reação ao racionalismo.

Ao estudarmos os aspectos espaciais, verificamos que é possível ultrapassar os limites reais do geográfico e avançar rumo ao misterioso e inexplicável, quando detalhamos os aspectos sombrios de Derry, desde sua fundação até a aventura vivida pelo clube dos otários. A residência assombrada da rua Neibolt configura-se como um elemento insólito, já que o espectador é levado para um mundo a ele familiar (uma casa abandonada), todavia a 
obra cinematográfica dispara, em certos momentos, mecanismos de surpresa, desorientação e medo.

Dessa forma, acreditamos que este trabalho proporcionou um novo olhar sobre a produção cinematográfica do medo. Discussões sobre cinema e fantástico são exploradas, mas não com tanta frequência. Sendo assim, releituras de películas no âmbito do fantástico tornam-se significativas, pois colocam em foco estudos que ficam à margem desta temática. A partir deles, podemos entender como o medo é construído pelas narrativas imagéticas.

\section{Referências}

ARÁUJO, Naiara Sales. Literatura fantástica, ficção científica e literatura gótica: interfaces e diálogos entrelaçados. São Luís: EDUFMA, 2018.

AUMONT, Jacques; MARIE, Michael. Dicionário teórico e crítico de cinema. Campinas: Papirus, 2001.

AUMONT, Jacques. A estética do filme. Campinas: Papirus, 1995.

AUMONT, Jacques; MARIE, Michel. A Análise do Filme. Lisboa: Edições Texto \& Grafia, 2013.

BACHELARD, Gaston. A poética do espaço. 2. ed. São Paulo: WMF Martins Fontes, 2008.

BAUMAN, Zygmunt. Medo líquido. Rio de Janeiro: Zahar, 2008.

FRANÇA, Júlio (org.). Poéticas do mal: a literatura do medo no Brasil. Rio de Janeiro: Bonecker, 2017.

FREUD, Sigmund. 0 estranho. In: FREUD, Sigmund. Obras psicológicas completas de Sigmund Freud. Rio de Janeiro: Imago, 1996. v. XVII, p. 237-273.

IT: a coisa. Direção: Andy Muschietti. [s.l]: New Line Cinema, 2017. 1 DVD. (134 min), son., color.

KING, Stephen. Dança macabra: o fenômeno do horror no cinema, na literatura e na televisão dissecado pelo mestre do gênero. Rio de Janeiro: Objetiva, 2003.

LOVECRAFT, Howard Phillips. Supernatural horror in literature. New York: Dover Publications, 1973.

MANGUEL, Alberto. Contos de Horror do século XIX. São Paulo: Companhia das Letras, 2005.

MARTIN, Marcel. A linguagem cinematográfica. São Paulo: Brasiliense, 2003. 
MESSIAS, Adriano. Todos os monstros da terra: bestiários do cinema e da literatura. São Paulo: EDUC, 2016.

METZ, Christian. Linguagem e cinema. São Paulo: Perspectiva, 1980.

MONTAIGNE, Michel de. Ensaio XVIII: do medo. In: MONTAIGNE, Michel de. Ensaios. São Paulo: Nova Cultural, 1991, pp. 39-40.

PEREIRA, Diogo Nonato Reis. Considerações sobre o fantástico. Memento, Três Corações, v. 4, n. 2, p. 1-21, 2013.

RAMOS, Jesus. Diccionario del guión audiovisual. Barcelona: Oceano Ambar, 2002.

ROGAK, Lisa. A biografia Stephen King: coração assombrado. Rio de Janeiro: Darkside Books, 2017.

SANTANA, Gelson. Cinema, comunicação e audiovisual. São Paulo: Alameda, 2007.

SIJLL, Jennifer Van. A narrativa cinematográfica: contando histórias com imagens em movimento. São Paulo: WMF Martins Fontes, 2017.

TODOROV, Tzvetan. Introdução à literatura fantástica. São Paulo: Perspectiva, 1981.

VANOYE, Francis; GOLIOT-LÉTÉ, Anne. Ensaio sobre a análise fílmica. Campinas: Papirus, 2012.

The construction of fear in It: reflections on Andy Muschietti's film, in the light of the fantastic genre

\begin{abstract}
In 2017, Stephen King's literary work It (1986) was made into a film by the hands of filmmaker Andy Muschietti. Born in Argentina in 1973, Muschietti gained notoriety in cinema due to the horror film Mama (2013). Muschietti has declared his passion for King's work since he was 14 and acknowledged the challenge of adapting that novel of over a thousand pages for the screen. This article aims to make a reflection on the construction of fear in the film It (2017), in the light of studies in the fantastic genre. We build on the literary scholarship of Lovecraft (1973), Todorov (1981), Bauman (2008), França (2017) and Araújo (2018), among others, as well as Aumont (1995) and Messias (2016) in the field of film studies. We argue that, looking for tropes of the fantastic genre and considering a film to be a piece of text composed of sounds, images and shots, we
\end{abstract}


can analyze how uncanny elements and other devices are deployed in $I t$ to build up the sensation of fear in the viewer.

\section{Keywords}

Fear. Cinema. Fantastic. Andy Muschietti.

\section{Autor correspondente}

Naiara Sales Araújo

naiara.sas2@gmail.com

\section{Como citar}

ARAÚJO, Naiara Sales; COSTA, José Antônio Moraes. A construção do medo em It: a coisa: reflexões sobre a narrativa cinematográfica de Andy Muschietti, à luz do gênero fantástico. Intexto, Porto Alegre, n. 52, e92525, jan./dez. 2021. DOI: http://dx.doi.org/10.19132/1807-8583202152.92525

Recebido em 03/05/2019

Aceito em 31/10/2019

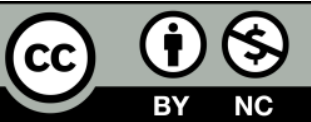

